\title{
miRNA-1207-5p is associated with cancer progression by targeting stomatin-like protein 2 in esophageal carcinoma
}

\author{
XUAN YANG $^{1}$, WENQIAO ZANG ${ }^{1}$, XIAOYAN XUAN ${ }^{1}$, ZHONGQUAN WANG $^{1}$, \\ ZHICAI LIU ${ }^{2}$, JINWU WANG ${ }^{2}$, JING CUI ${ }^{1}$ and GUOQIANG ZHAO ${ }^{1}$ \\ ${ }^{1}$ College of Basic Medical Sciences, Zhengzhou University, Zhengzhou 450001; \\ ${ }^{2}$ Tumor Hospital of Linzhou City, Linzhou, Henan 456500, P.R. China
}

Received December 19, 2014; Accepted February 2, 2015

DOI: $10.3892 /$ ijo.2015.2900

\begin{abstract}
Newly discovered intrinsic regulators, the miRNAs regulate gene expression by binding to the 3'-untranslated regions of the genome. Accumulating studies have indicated that miRNAs are aberrantly expressed in various human cancers. We found that miRNA-1207-5p (miR-1207-5p) was markedly downregulated in esophageal carcinoma (EC) tissues, and was correlated with EC differentiation, pathological stage and lymph node metastasis. Rates of apoptosis were increased and cell invasion ability was decreased in EC9706 and EC-1 cells transfected with a miR-1207-5p mimic. Stomatin-like protein 2 (STOML-2) was predicted to be a potential target of miR-1207-5p by bioinformatics analysis and this was confirmed by luciferase assay and western blotting. Our study showed that STOML-2 was negatively regulated by miR-1207-5p. Furthermore, overexpression of STOML-2 abolished the miR-1207-5p anti-invasion function. Based on these results, we proposed that miR-1207-5p might act as a potential therapeutic target in the treatment of EC.
\end{abstract}

\section{Introduction}

MicroRNAs (miRNAs) are a large family of non-coding RNAs, typically 18-25 nucleotides in length, that are highly conserved and endogenously expressed in many species. Newly discovered intrinsic regulators, the miRNAs regulate gene expression by binding to the 3'-untranslated regions (3'-UTR) (1-4). Rapidly accumulating studies have indicated that miRNAs are differentially expressed in various human cancers, including non-small cell lung cancer, esophageal cancer, colorectal cancer, bladder cancer and lymphocytic leukemia, and they function as tumor suppressors and oncogenes (4-8). It has been reported that

Correspondence to: Professor Guoqiang Zhao or Professor Jing Cui, College of Basic Medical Sciences, Zhengzhou University, Kexue Road 100, Zhengzhou 450001, P.R. China

E-mail: zhaogq@zzu.edu.cn

E-mail: cuij@zzu.edu.cn

Key words: miRNA-1207-5p, stomatin-like protein 2, esophageal carcinoma, invasion, apoptosis
miRNAs are involved in various cellular processes such as differentiation, migration and apoptosis.

Aberrant expression of miRNAs has been reported in esophageal carcinoma (EC) $(9,10)$, and may play a role in the development of EC. We screened a series of miRNAs in EC tissues and in comparison with their normal counterparts using miRNA microarrays. Notably, miR-1207-5p was expressed at a lower level in EC tissues. Previous reports have shown that miR-1207-5p has differential expression in breast cancer and in human corneal epithelial cells $(11,12)$. In addition, miR-1207-5p acted as a suppressor in gastric cancer, inhibited the growth of tumors by targeting human telomerase reverse transcriptase, and resulted in reduced tumor volume (13); miR-1207-5p was also shown to regulate heparin binding epidermal growth factor expression, to be involved in extracellular matrix accumulation and to be associated with disease severity in nephropathy $(14,15)$. However, the functions of miR-1207-5p in EC have not been reported. We used TargetScan 6.2 (http://www.targetscan. org) and miRBase (http://www.mirbase.org) to predict that the target of miR-1207-5p is STOML-2, which is a member of the stomatin family, but differs from other members of the family by the lack of a hydrophobic membrane anchor at its $\mathrm{N}$-terminus (16-18). Reports have indicated that STOML-2 was upregulated in several kinds of tumor tissue and was involved in invasion and metastasis of cancers including esophageal cancer, gastric cancer, breast cancer and glioma (19-23). Inhibition of STOML-2 was able to decrease cell growth and proliferation, and reduced migratory speed and invasive ability $(24,25)$.

Herein, we report that miR-1207-5p was markedly downregulated in $49 \mathrm{EC}$ specimens, and STOML-2 was correspondingly upregulated. Rates of apoptosis were found to be increased in EC9706 and EC-1 cells transfected with a miR-1207-5p mimic. We further measured the level of phospho-I $\kappa \mathrm{B} \alpha(\mathrm{p}-\mathrm{I} \kappa \mathrm{B} \alpha)$, an important molecule in the NF- $\mathrm{B}$ signal pathway, which was downregulated in miR-1207-5p-transfected cells. Taken together, our results suggested that miR-1207-5p affected cell invasion and apoptosis in EC cells by targeting STOML-2.

\section{Materials and methods}

Patient information and specimens. Tumor center and marginal tissues $(n=49)$ were collected at the First Affiliated Hospital of Zhengzhou University and Tumor Hospital of Linzhou City 
Henan, China, with the consent of all the patients and approval by the Ethics Committee of Zhengzhou University. Tissue samples were stored at $-80^{\circ} \mathrm{C}$ until analysis. Patients who had undergone preoperative adjuvant therapy were excluded. The clinicopathological characteristics of the 49 EC patients are listed in Table I. Post-operative pathological staging is determined for each individual according to the seventh edition of the UICC/AJCC TNM staging system for EC.

Cell lines. Human esophageal cancer EC9706 and EC-1 cells were purchased from the Cell Bank of the Chinese Academy of Medical Sciences (Beijing, China). The two cell lines were maintained in RPMI-1640 medium with $100 \mathrm{U} / \mathrm{ml}$ penicillin and $100 \mu \mathrm{g} / \mathrm{ml}$ streptomycin (Solarbio, Beijing, China) supplemented with $10 \%$ fetal bovine serum (Gibco, Carlsbad, CA, USA) and incubated in a humidified atmosphere of $5 \% \mathrm{CO}_{2}$ at $37^{\circ} \mathrm{C}$.

Total RNA isolation and quantitative reverse transcription PCR analysis. Total RNA was extracted from tissues and cells using the TRIzol reagent (Invitrogen, Carlsbad, CA, USA); cDNA was synthesized using the RevertAid First Strand cDNA (K1621; Thermo Fisher Scientific, Waltham, MA, USA) in $20 \mu \mathrm{l}$ containing $2 \mu \mathrm{l}$ of RNA, $1 \mu \mathrm{l}$ of random hexamer primer, $9 \mu \mathrm{l}$ of Nuclease-free water, $4 \mu \mathrm{l}$ of $5 \mathrm{X}$ reaction buffer, $1 \mu \mathrm{l}$ of RNase inhibitor $(20 \mathrm{U} / \mu \mathrm{l}), 2 \mu \mathrm{l}$ of $10 \mathrm{mM}$ dNTPs mix and $1 \mu \mathrm{l}$ of reverse transcriptase $(200 \mathrm{U} / \mu \mathrm{l})$. The mixture was incubated for $5 \mathrm{~min}$ at $25^{\circ} \mathrm{C}$, followed by $60 \mathrm{~min}$ at $42^{\circ} \mathrm{C}$, and then at $70^{\circ} \mathrm{C}$ for 5 min. qRT-PCR was performed using SYBR Green I (DRR041A; Takara, Dalian, China) following the kit manual. A specific two step Stemaim-it miR qRT-PCR quantitation kit (LM-0101A; Novland Co. Ltd., Shanghai, China) was used to detect miR-1207-5p levels. The primers for miR-1207-5p were 5'-GTCGTATCCAGTGCAGGGTCCGAGGTATT CGCACTGGATACGACCCCCTCC-3' (stem-loop RT primer), 5'-TCCGAAGGCAGGGAGGCAG-3' (forward), 5'-GTGCAGGGTCCGAGGT-3' (reverse). The primers for U6 were 5'-GTCGTATCCAGTGCAGGGTCCGAGGTATTC GCACTGGATACGACAAAATA-3' (stem-loop RT primer), 5'-TCCGATCGTGAAGCGTTC-3' (forward), 5'-GTGCAGGG TCCGAGGT-3' (reverse). Reaction solution including $15 \mu \mathrm{l}$ of master mix (2X), $1 \mu$ l of enzyme mix, $1 \mu$ l of miR primer mix $(0.1 \mu \mathrm{M}), 2 \mu \mathrm{l}$ of cDNA and $11 \mu \mathrm{l}$ of RNase free water in a final volume of $30 \mu \mathrm{l}$, was pretreated for $3 \mathrm{~min}$ at $94^{\circ} \mathrm{C}$, then incubated for $20 \mathrm{sec}$ at $94^{\circ} \mathrm{C}$, followed by $40 \mathrm{sec}$ at $62^{\circ} \mathrm{C}$ for 40 cycles. qRT-PCR was carried out on 7500 Fast Real-time PCR system (Applied Biosystems), the relative expression levels of the miRNA were calculated using the comparative $\mathrm{Ct}$ $\left(2^{-\Delta \mathrm{Ct}}\right)$ and were normalized to U6 small nuclear RNA.

Transient transfections. EC9706 and EC-1 were transfected with $50 \mathrm{nM}$ miR-1207-5p mimic or negative control (NC, GenePharma, Shanghai, China). In detail, EC9706 and EC-1 were cultured in 6 -well plates at a density of $1.5 \times 10^{5}$ cells/well; Lipofectamine ${ }^{\mathrm{TM}}$ 2000 (Invitrogen) was used according to the manufacturer's protocol. The effects of transfection with miR-1207-5p mimic were evaluated in each experiment by qRT-PCR.

Cell proliferation assay. The cell counting kit-8 assay (CK04-11; CCK-8, Dojindo, Rockville, MD, USA) was used to detect cell proliferation. A total of $1 \times 10^{4}$ cells/well were placed in a
Table I. Clinicopathological characteristics of patients with esophageal carcinoma.

\begin{tabular}{ll}
\hline Characteristics & $\begin{array}{c}\text { No. of patients } \\
(\mathrm{n}=49)\end{array}$ \\
\hline Gender (male/female) & $33 / 16$ \\
Age (years) ( $\geq 60 /<60)$ & $31 / 18$ \\
Tumor location (middle/lower) & $38 / 11$ \\
Lymph node metastasis (negative/positive) & $33 / 16$ \\
Differentiation (well/moderate/poor) & $15 / 25 / 9$ \\
TNM stage (I/II/III) & $13 / 24 / 12$ \\
\hline
\end{tabular}

96-well plate, and grown for 24, 48, 72 and $96 \mathrm{~h}$. The CCK-8 solution was added to each well at $10 \mu \mathrm{l} /$ well, and incubated at $37^{\circ} \mathrm{C}$ for $2 \mathrm{~h}$. The absorbance at $450 \mathrm{~nm}$ was measured daily over four consecutive days by a microplate reader (Bio-Rad, Japan). Results were collected from three separate experiments with five replicate wells per group.

Cell invasion assays. Cell invasion assays were performed using a transwell assay $(8.0 \mu \mathrm{m}$, Corning, NY, USA); the upper chambers were coated with Matrigel basement membrane matrix (356234; BD Biosciences, San Jose, CA, USA) in serum-free RPMI-1640 for $3 \mathrm{~h}$ at $37^{\circ} \mathrm{C}$. EC9706 and EC-1 cells were suspended in serum-free medium at a density of $2 \times 10^{5}$ cells $/ \mathrm{ml}$ at $48 \mathrm{~h}$ post-transfection and placed into the upper chamber (200 $\mu \mathrm{l} /$ well). Medium containing $10 \%$ FBS (500 $\mu \mathrm{l}$ ) was added to the lower chamber, followed by incubation at $37^{\circ} \mathrm{C}$ in $5 \% \mathrm{CO}_{2}$ for $30 \mathrm{~h}$. Following this, the medium and cells in the upper chamber were removed, and the cells that had migrated to the other side of the membrane were fixed in $4 \%$ paraformaldehyde, stained with $10 \%$ crystal purple for $>30 \mathrm{~min}$, and counted in three random fields under an inverted microscope (Leica Microsystems, Wetzkar, Germany).

Apoptosis assay. Cells were collected at $24 \mathrm{~h}$ post-transfection and stained with Annexin V-FITC apoptosis detection kit (KGA107; KeyGen, Nanjing, China) according to the instruction manual. Apoptosis was analyzed using a FACScan ${ }^{\circledR}$ flow cytometer equipped with CellQuest software (BD Biosciences).

Western blot analysis. Total protein from cultured cells were obtained using NP-40 lysis buffer (P0013F; Beyotime, Haimen, China) with $1 \mathrm{mM}$ phenylmethanesulfonyl fluoride (ST506; Beyotime). The protein concentrations were determined using a BCA protein assay kit (P0012; Beyotime) according to the protocol. Protein lysates were subjected to SDS-PAGE, and were transferred into polyvinylidene fluoride (PVDF) membranes. Membranes were blocked with 5\% non-fat milk in TBST for $2 \mathrm{~h}$ at room temperature and incubated overnight at $4^{\circ} \mathrm{C}$ with anti-STOML-2 (1:2,000, Proteintech ${ }^{\mathrm{TM}}$, Wuhan, China), antiBCL-2 (1:1,500, Proteintech), or anti-pIкB $\alpha$ (pSer32, 1:2,000, Epitomics, Burlingame, CA, USA). Horseradish peroxidaseconjugated goat anti-rabbit IgG (1:3,000, Proteintech) was used for detection of immunoreactive proteins. Signals were detected using ECL kit (P0018; Beyotime). An antibody against $\alpha$-tubulin (1:2,000, Proteintech) served as endogenous control. 
Table II. Levels of expression of miRNA-1207-5p and STOML-2 mRNA in EC samples.

\begin{tabular}{|c|c|c|c|c|c|}
\hline Variables & $\mathrm{n}$ & $\begin{array}{c}\text { miRNA-1207-5p } \\
(\text { Median } \pm \text { SD })\end{array}$ & P-value & $\begin{array}{c}\text { STOML-2 } \\
(\text { Median } \pm \text { SD })\end{array}$ & P-value \\
\hline Gender & 49 & & & & \\
\hline Male & 33 & $0.4142 \pm 0.10604$ & 0.320 & $2.0942 \pm 0.24529$ & 0.571 \\
\hline Female & 16 & $0.3813 \pm 0.11099$ & & $2.1334 \pm 0.17492$ & \\
\hline Age & 49 & & & & \\
\hline$<60$ & 18 & $0.4106 \pm 0.12642$ & 0.729 & $2.1079 \pm 0.25835$ & 0.983 \\
\hline$\geq 60$ & 31 & $0.3994 \pm 0.09716$ & & $2.1065 \pm 0.20544$ & \\
\hline Tumor location & 49 & & & & \\
\hline Middle & 38 & $0.3892 \pm 0.09488$ & 0.085 & $2.1442 \pm 0.19865$ & $0.029^{\mathrm{a}}$ \\
\hline Lower & 11 & $0.4527 \pm 0.13741$ & & $1.9787 \pm 0.26592$ & \\
\hline Lymph node metastasis & 49 & & & & \\
\hline Negative & 33 & $0.4509 \pm 0.09112$ & 0 & $0286 \pm 0.22070$ & $0.000^{\mathrm{b}}$ \\
\hline Positive & 16 & $0.3056 \pm 0.06491$ & & \pm 0.12119 & \\
\hline Differentiation & 49 & & & & \\
\hline Well & 15 & $0.4720 \pm 0.11283$ & & $42 \pm 0.22912$ & $0.003^{\mathrm{b}}$ \\
\hline Moderate & 25 & $0.4116 \pm 0.07238$ & & $2.1267 \pm 0.20930$ & \\
\hline Poor & 9 & $0.2667 \pm 0.03841$ & & $2.2739 \pm 0.10592$ & \\
\hline TNM stage & 49 & & & & \\
\hline I & 13 & $0.4631 \pm 1.0980$ & $0.000^{\mathrm{b}}$ & $2.0344 \pm 0.28936$ & $0.043^{\mathrm{a}}$ \\
\hline II & 24 & $0.4271 \pm 0.08590$ & & $2.0787 \pm 0.20213$ & \\
\hline III & 12 & $0.2917 \pm 0.05424$ & & $2.2424 \pm 0.11626$ & \\
\hline
\end{tabular}

${ }^{\mathrm{a}} \mathrm{P}<0.05 ;{ }^{\text {b }} \mathrm{P}<0.01$.

3'-UTR luciferase reporter assay. To construct the STOML-2 3'-UTR luciferase reporter vector, the 3'-UTR of human STOML-2 (NM_013442, bases 1173-1431) fragment containing the seed sequence of mature miR-1207-5p was amplified by PCR from human genomic DNA. The primers for STOML-2 3'-UTR were as follows: 5'-AAGCTCGAGTGGAGCTGGG CTTGGCCAGGGAGTCTG-3' (forward), 5'-GGGTCTAGA TGGTTTGCCACTGGTGAGTTTATTACA-3' (reverse). The fragment was cloned into the pmirGLO vector (E1330; Promega, Madison, WI, USA) downstream of the luciferase reporter gene to construct the recombinant vector, which was named STOML-2-3'-UTR-WT. The mutant STOML-2 3'-UTR fragment was generated by overlap extension PCR. The primers were as follows: 5'-AAGCTCGAGTGGAGCTGGG CTTGGCCAGGGAGTCTG-3' (primer 1 forward), 5'-CTAGC TTGGGACGGTAGATTTTGGTTTTTATTTTTTTATTTG-3' (primer 1 reverse). 5'-AATCTACCGTCCCAAGCTAGAGC CAGAATCAGG-3' (primer 2 forward), 5'-GGGTCTAGA TGGTTTGCCACTGGTGAGTTTATTACA-3' (primer 2 reverse). 5'-AAGCTCGAGTGGAGCTGGGCTTGGCCAGG GAGTCTG-3' (primer 3 forward), 5'-GGGTCTAGATGGTT TGCCACTGGTGAGTTTATTACA-3' (primer 3 reverse). In detail, with the STOML-2 3'-UTR fragment serving as a template, primer 1 and primer 2 were used to amplify fragment 1 and fragment 2; the two fragments and primer 3 were used to generate the full length mutant fragment. Subsequently, the mutant fragment was inserted into the pmirGLO vector (E1330; Promega) and named STOML-2-3'-UTR-MT. For the luciferase reporter assay, human HEK293T cells were transiently co-transfected with $50 \mathrm{nM}$ of miRNA (miR-1207-5p mimic or miR-1207-5p NC) and $50 \mathrm{nM}$ of recombinant vectors (STOML-2-3'-UTR-WT or STOML-2-3'-UTR-MT) using Lipofectamine 2000. Luciferase activities were analyzed with a Dual-Luciferase Reporter assay system (E1910; Promega) and a CentroXS3 LB960 luminometer (Berthold, Germany) at $24 \mathrm{~h}$ post-transfection.

Statistical analysis. Statistical analyses were carried out using SPSS 17.0 software. Numerical results were presented as mean \pm standard deviation. One-way analysis of variance was used to evaluate the data. Results were considered significant when $\mathrm{P}<0.05$.

\section{Results}

The levels of miR-1207-5p expression are downregulated and STOML-2 are upregulated in EC tissues. To determine whether miR-1207-5p was involved in the tumorigenesis of EC, we investigated miR-1207-5p expression in 49 matched EC specimens and adjacent non-tumor tissues by qRT-PCR. As shown in Fig. 1A, the levels of miR-1207-5p were lower in tumor tissues than in adjacent non-tumor tissues $(\mathrm{P}<0.01)$. We also examined the possible correlation of miR-1207-5p expression with the occurrence of poor tumor differentiation and lymph node metastasis $(\mathrm{P}<0.05$; Fig. $1 \mathrm{~B}$ and Table II) in all patients with EC. However, there were no significant asso- 

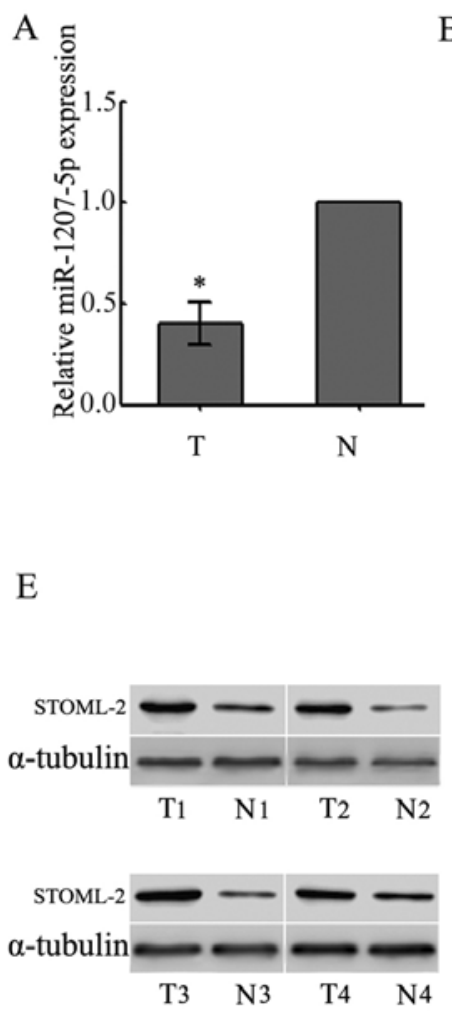

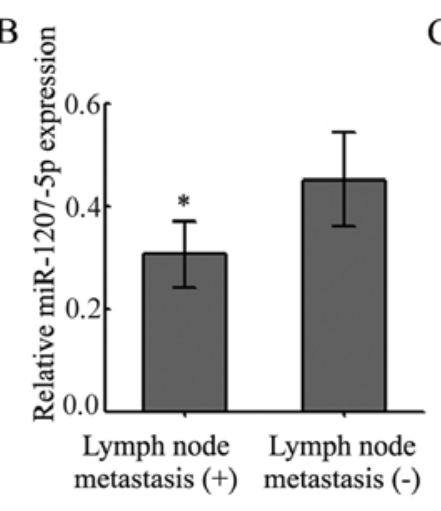

C

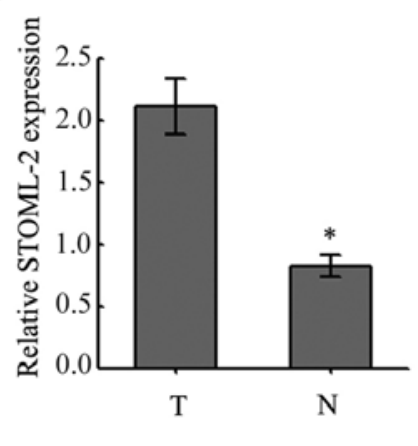

D

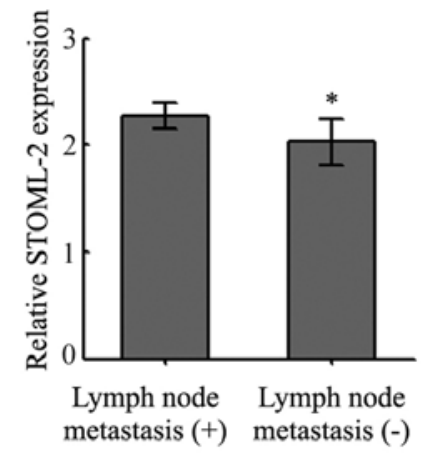

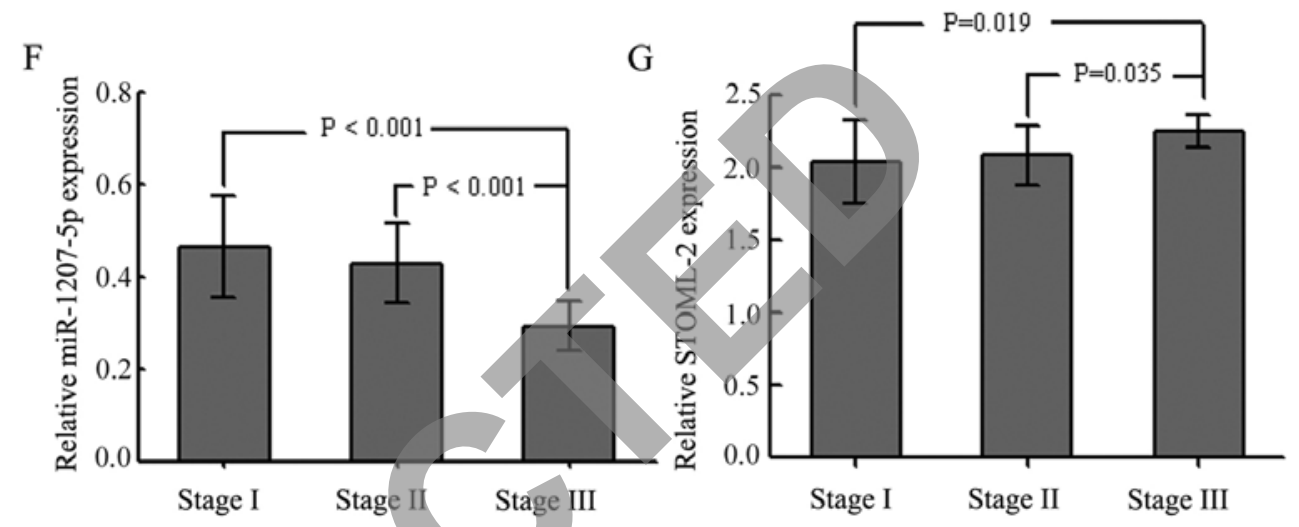

Figure 1. Levels of expression of miR-1207-5p and STOML-2 mRNA in EC tissues and clinical significance. (A) Relative expression of miR-1207-5p in paired EC tissues and adjacent non-tumor tissues $(\mathrm{P}<0.05)$. (B) miR-1207-5p expression in the metastasis-free group was significantly higher than in the metastasispositive group $(\mathrm{P}<0.01)$. (C) Compared with adjacent non-cancerous tissues, the levels of STOML-2 mRNA expression in EC tissues were higher $(\mathrm{P}<0.01)$ (D) The level of expression of STOML-2 mRNA in the metastasis-positive group was higher than in the metastasis-free group (P<0.01). (E) Western blot results showed that level of STOML-2 protein expression in EC tissues was higher than in adjacent non-cancerous tissues. (F) The expressions of miR-1207-5p were lower in patients with tumors of higher pathological stage than in those with tumors of lower pathological stage (P<0.01). (G) The expressions of STOML-2 were higher in patients with tumors of higher pathological stage than in those with tumors of lower pathological stage $(\mathrm{P}<0.05)$. $\mathrm{T}$, cancerous tissue $(\mathrm{n}=49)$; $\mathrm{N}$, adjacent non-cancerous tissue $(\mathrm{n}=49)$.

ciations between the levels of miR-1207-5p expression and gender, age or tumor location ( $\mathrm{P}>0.05$; Table II). Compared to the counterpart tissues, the levels of STOML-2 in EC tissues were greatly increased ( $\mathrm{P}<0.05$; Fig. $1 \mathrm{C}$ and $\mathrm{E}$ and Table II). STOML-2 expression levels in EC tissues were related to lymph node metastases and the differentiation status $(\mathrm{P}<0.05$; Fig. 1D and Table II), but not to gender, age or tumor location ( $\mathrm{P}>0.05$; Table II). The expression of miR-1207-5p and STOML-2 exhibited significant differences at different TNM stages ( $\mathrm{P}<0.05$; Fig. $1 \mathrm{~F}$ and $\mathrm{G}$ and Table II). The results also showed that miR-1207-5p was negatively correlated with STOML-2. Thus, these results indicated that downregulation of miR-1207-5p might play an important role in the progression and development of EC.

Overexpression of miR-1207-5p inhibits proliferation in EC9706 and EC-1 cells. To investigate whether miR-1207-5p functions as a tumor suppressor, the effects of upregulation of miR-1207-5p on the proliferation of EC cells were determined in vitro. The levels of miR-1207-5p expression in EC cells were detected by qRT-PCR. The levels of miR-1207-5p in EC9706 and EC-1 cells transfected with the miR-1207-5p mimic were higher than in the control groups, including the non-transfected blank group (blank) and the negative control group ( $\mathrm{NC})(\mathrm{P}<0.01$, Fig. $2 \mathrm{~A})$. In contrast, the levels of
STOML-2 were found to be lower in the miR-1207-5p group when compared with the blank and NC groups (Fig. 2B). As shown in Fig. 2C and D, miR-1207-5p overexpression significantly decreased the growth rate of EC cells. The absorbance at $450 \mathrm{~nm}$ for the miR-1207-5p group at 48, 72 and $96 \mathrm{~h}$ was significantly decreased $(\mathrm{P}<0.05)$ in both EC9706 and EC-1 cells. However, there were no significant differences between the blank and NC groups $(\mathrm{P}>0.05)$.

Overexpression of miR-1207-5p induces apoptosis and restricts cell invasion of EC cells. To determine whether miR-1207-5p was contributing to apoptosis, we performed flow cytometric analysis of EC cells after transfection with miR-1207-5p mimic or NC. The results revealed that the level of apoptosis of cells transfected with the miR-1207-5p mimic was significantly increased when compared with the blank and NC groups $(\mathrm{P}<0.05$; Fig. $3 \mathrm{~A})$. These results suggested that upregulation of miR-1207-5p was able to induce apoptosis in EC9706 and EC-1 cells.

Transwell assays were used to test the effect of miR-1207-5p on cells invasion. Cells transfected with miR-1207-5p showed a remarkable decrease in invasive capacity compared with cells in the blank and NC groups $(\mathrm{P}<0.01$, Fig. 3B). However, there were no significant differences between the blank and $\mathrm{NC}$ groups. In summary, these results indicated that overex- 
A.
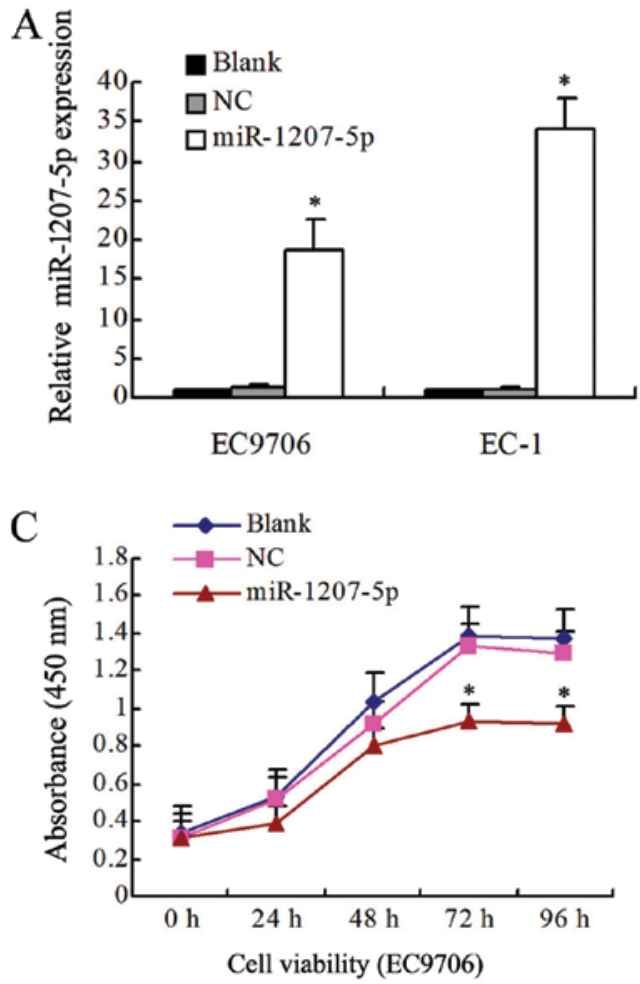

B
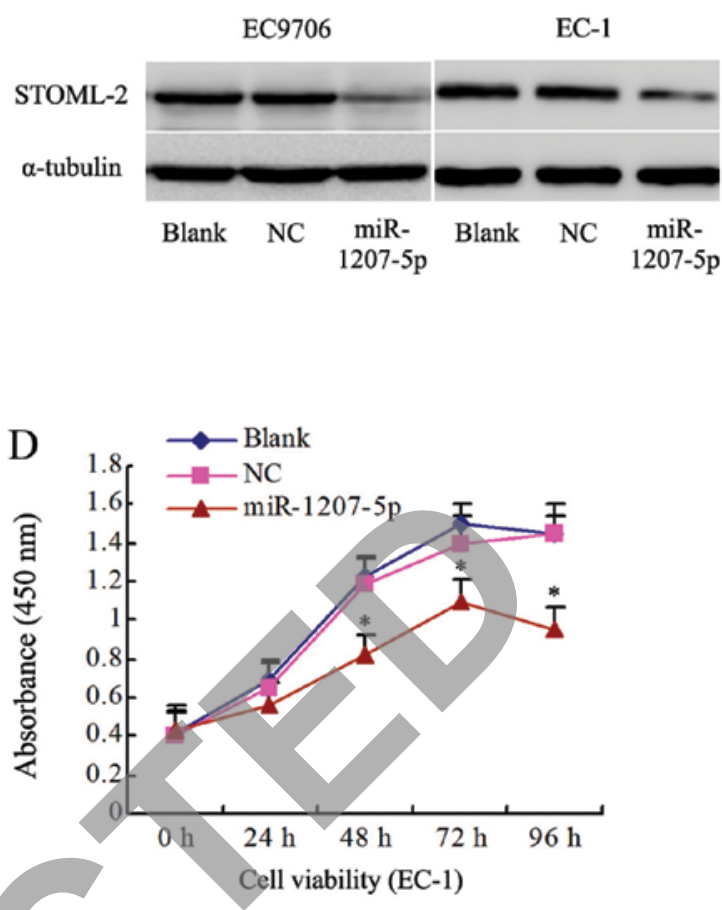

Figure 2. Effects of miR-1207-5p overexpression in vitro on proliferation of EC cells. Levels of expression of miR-1207-5p were measured by qRT-PCR in three treatment groups: miR-1207-5p, NC, blank. The levels of miR-1207-5p were higher in transfected with miR-1207-5p mimic group than in the other two groups $(\mathrm{P}<0.01)$. (B) Levels of STOML-2 expression were determined with western blot assays. The results showed that the level of STOML-2 expression in the miR-1207-5p group was lower than in the control groups. (C and D) The proliferation of cells was detected using a CCK8 assay at 0,24,48 72 and $96 \mathrm{~h}$ after transfection $($ P $<0.05)$. miR-1207-5p, cells transfected with miR-1207-5p mimic; NC, cells transfected with scrambled miR-1207-5p negative control; blank, untransfected cells.
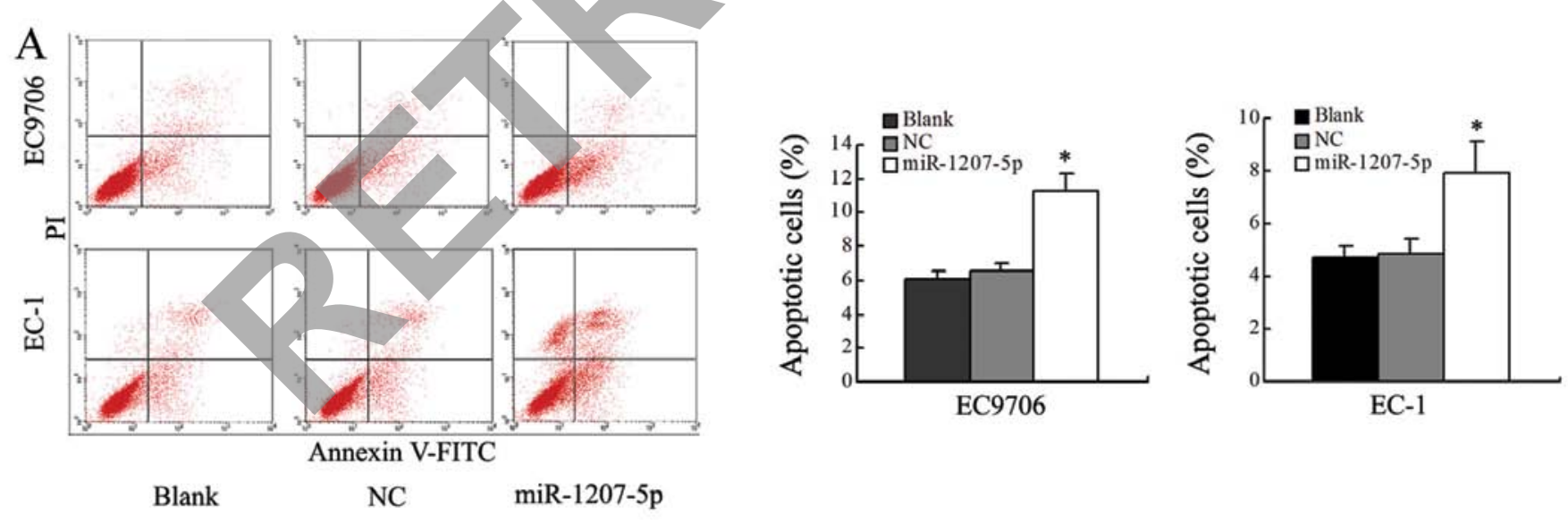

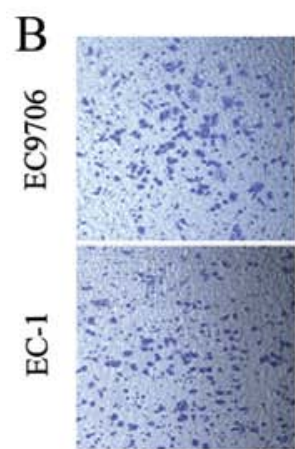

Blank

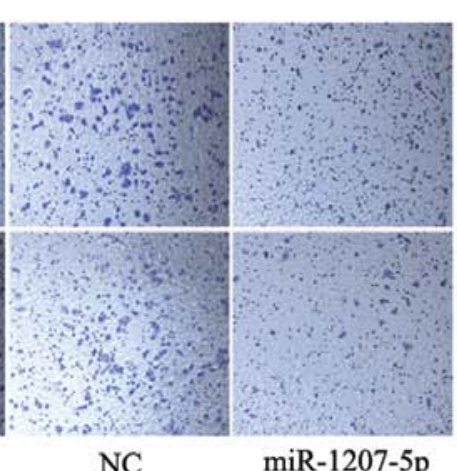

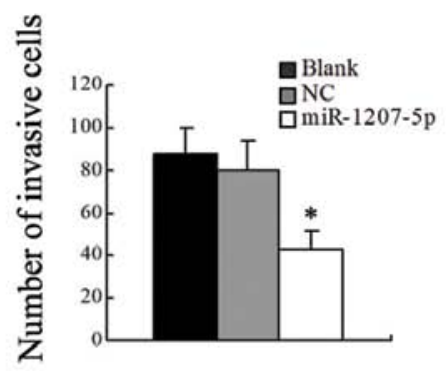

EC9706

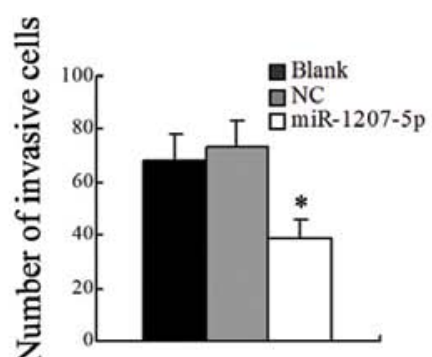

EC-1

Figure 3. Effects of upregulation of miR-1207-5p on apoptosis and invasion of EC9706 and EC-1. (A) Cell apoptosis was detected by Annexin V-FITC/PI assay. (B) Transwell assays were used to assess the invasive ability. " $\mathrm{P}<0.05$; miR-1207-5p, cells transfected with miR-1207-5p mimic; NC, cells transfected with scrambled miR-1207-5p negative control; blank, untransfected cells. 
A

Position 68-75 of STOML-2 3'-UTR

wild $\quad 5^{\prime}$...UUCUGGCUCUAGCUUCCCUGCCA... miR-1207-5p 3' GGGGAGGGUCGGAGGGACGGU mutation $\quad 5^{\prime}$...UUCUGGCUCUAGCUUGGGACGGA...

$\mathrm{C}$

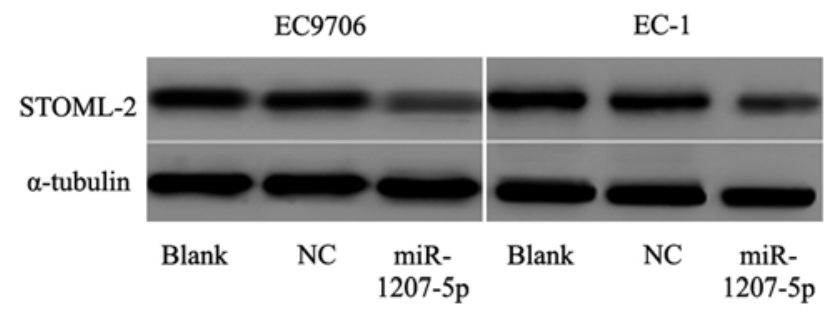

$\mathrm{B}$

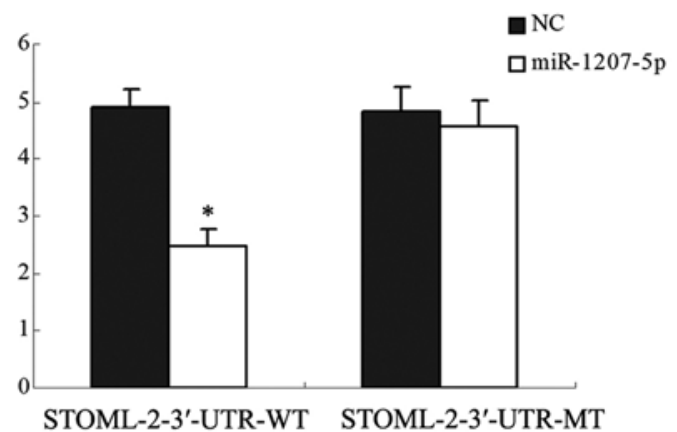

$\mathrm{D}$

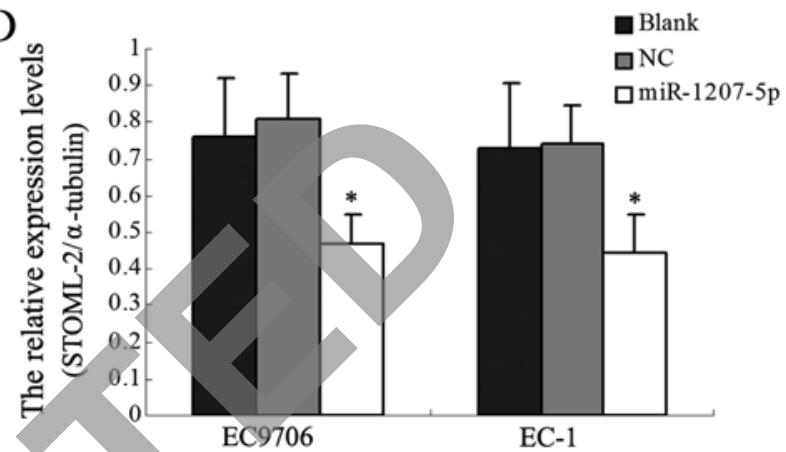

Figure 4. miR-1207-5p directly targets STOML-2 in EC9706 and EC-1 cells. (A) The sequence of miR-1207-5p matches the 3'-UTRs of STOML-2. The mutated nucleotides of the 3'-UTR of STOML-2 are underlined. (B) The relative luciferase activities of STOML-2-3'-UTR-WT and STOML-2-3'-UTR-MT were calculated at $24 \mathrm{~h}$ post-transfection. (C and D) Western blot analysis of the levels of expression of STOML-2 in EC9706 and EC-1 cells. "P<0.05; miR-1207-5p, cells transfected with miR-1207-5p mimic; NC, cells transfected with scrambled miR-1207-5p negative control; blank, untransfected cells. STOML-2-3'-UTR-WT, transfected with recombinant vector STOML-2-3'-UTR-WT; STOML-2-3'-UTR-MT, transfected with recombinant vectors STOML2-3'-UTR-MT.

pression of miR-1207-5p decreased the invasive ability of both EC9706 and EC-1 cells.

miR-1207-5p directly targets the STOML-2 gene by binding with the 3'-UTR. The TargetScan and miRBase database predicted that the 3'-UTR of STOML-2 mRNA contained the seed region for miR-1207-5p. To verify this prediction, we used a dual-luciferase reporter system. The wild STOML-2 3'-UTR sequence and the mutant STOML-2 3'-UTR sequence were inserted into the pmirGLO vector to construct the recombinant vectors STOML-2-3'-UTR-WT and STOML-2-3'UTR-MT. The recombinant vectors were co-transfected with miR-1207-5p mimic or NC into human HEK293T cells. The luciferase activity of the reporter was decreased in the group co-transfected with miR-1207-5p mimic and the STOML-23'-UTR-WT ( $\mathrm{P}<0.05$, Fig. 4A and B). However, the luciferase activity of the reporter was unaffected by co-transfection with miR-1207-5p and the STOML-2-3'-UTR-MT. Western blot analysis indeed showed that STOML-2 protein expression was significantly inhibited in EC9706 and EC-1 cells transfected with the miR-1207-5p mimic, compared with control cells $(\mathrm{P}<0.05$, Fig. $4 \mathrm{C}$ and $\mathrm{D})$. These results indicated that miR-1207-5p might inhibit STOML-2 expression by binding directly to a putative seed region in the 3'-UTR of STOML-2.

Expression of STOML-2 abrogates the anti-invasion function of miR-1207-5p. The previous studies suggested that STOML-2 was relevant to tumor invasion, so we constructed an expression verctor containing the OFR of STOML-2 instead of the 3'-UTR of STOML-2 (pcDNA3.1-STOML-2) to explore whether STOML-2 was involved in the miR-1207-5p-related invasion. We found that transfection of pcDNA3.1-STOML-2 separately, or co-transfection with the miR-1207-5p mimic, resulted in increased expression of STOML-2 (Fig. 5A and B). Interestingly, the average numbers of invaded cells were correspondingly increased in the above groups $(\mathrm{P}<0.05$; Fig. 5C and D). Cells transfected with miR-1207-5p mimic separately showed a decrease in invasive capacity compared with the control groups $(\mathrm{P}<0.05)$. These results indicated that the overexpression of STOML-2 abrogated the anti-invasion function of miR-1207-5p.

miR-1207-5p might be involved in the NF- $\kappa B$ signal pathway. In the above studies, we found that upregulation of miR-1207-5p decreased the expression of STOML-2. Other researchers have reported that silencing STOML-2 in cells significantly inhibited the $\mathrm{NF}-\kappa \mathrm{B}$ activity and decreased the levels of expression of NF- $\kappa \mathrm{B}$ target genes, including BcL-xL. Therefore, we examined whether miR-1207-5p has effects on the NF- $\mathrm{B}$ pathway by analyzing the phosphorylation of the main signaling molecule, I $\kappa \mathrm{B} \alpha$, and $\mathrm{Bcl}-2$, one of the $\mathrm{NF}-\kappa \mathrm{B}$ target genes. As shown in Fig. $6 \mathrm{~A}, \mathrm{p}-\mathrm{I} \kappa \mathrm{B} \alpha$ was significantly reduced in miR-1207-5p-transfected EC cells compared with the control cells. It was found that Bcl-2 expression was downregulated in miR-1207-5p-transfected cells (Fig. 6B). These results suggested that downregulation of STOML-2 protein by miR-1207-5p might be involved in the NF- $\kappa$ B activation pathway in EC cells. 
A

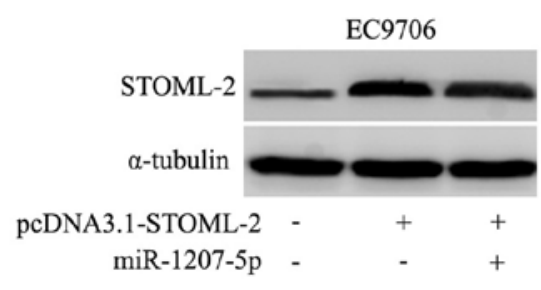

B

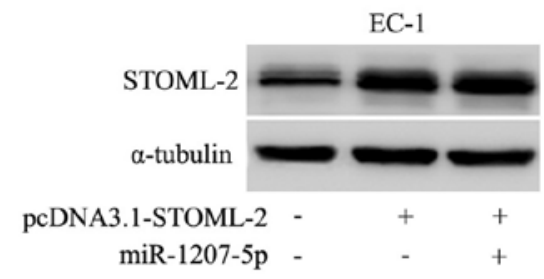

$\mathrm{C}$

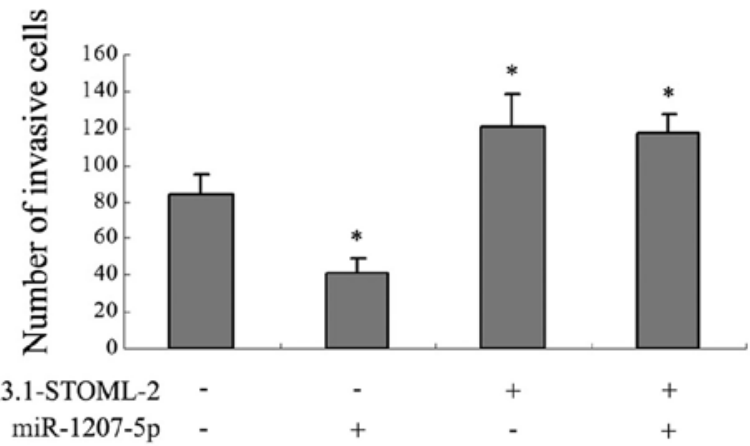

$\mathrm{D}$

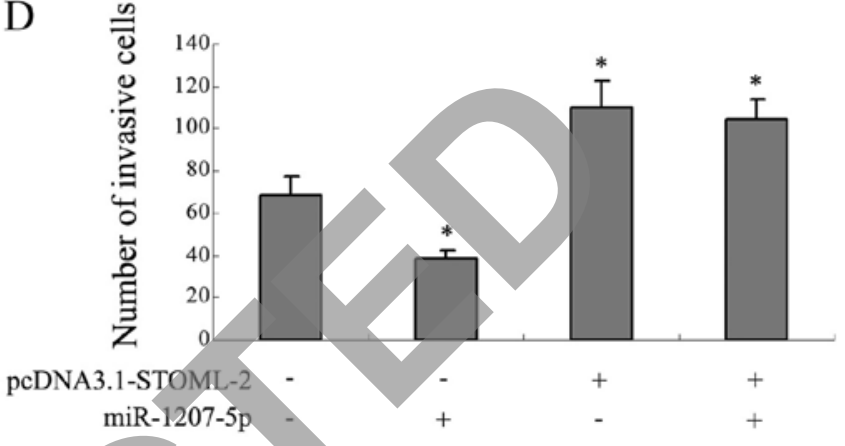

Figure 5. Expression of STOML-2 abrogates the anti-migratory effect of miR-1207-5p. (A and B) Transfection with pcDNA3.1-STOML-2 separately or cotransfection with the miR-1207-5p mimic increased STOML-2 expression. (C and D) Transfection with pcDNA3.1-STOML-2 increased the average number of invaded cells, abrogated the anti-migratory effect of miR-1207-5p. miR-1207-5p, cells transfected with miR-1207-5p mimic; pcDNA3.1-STOML-2, cells transfected with pcDNA3.1-STOML-2. ${ }^{*} \mathrm{P}<0.05$.
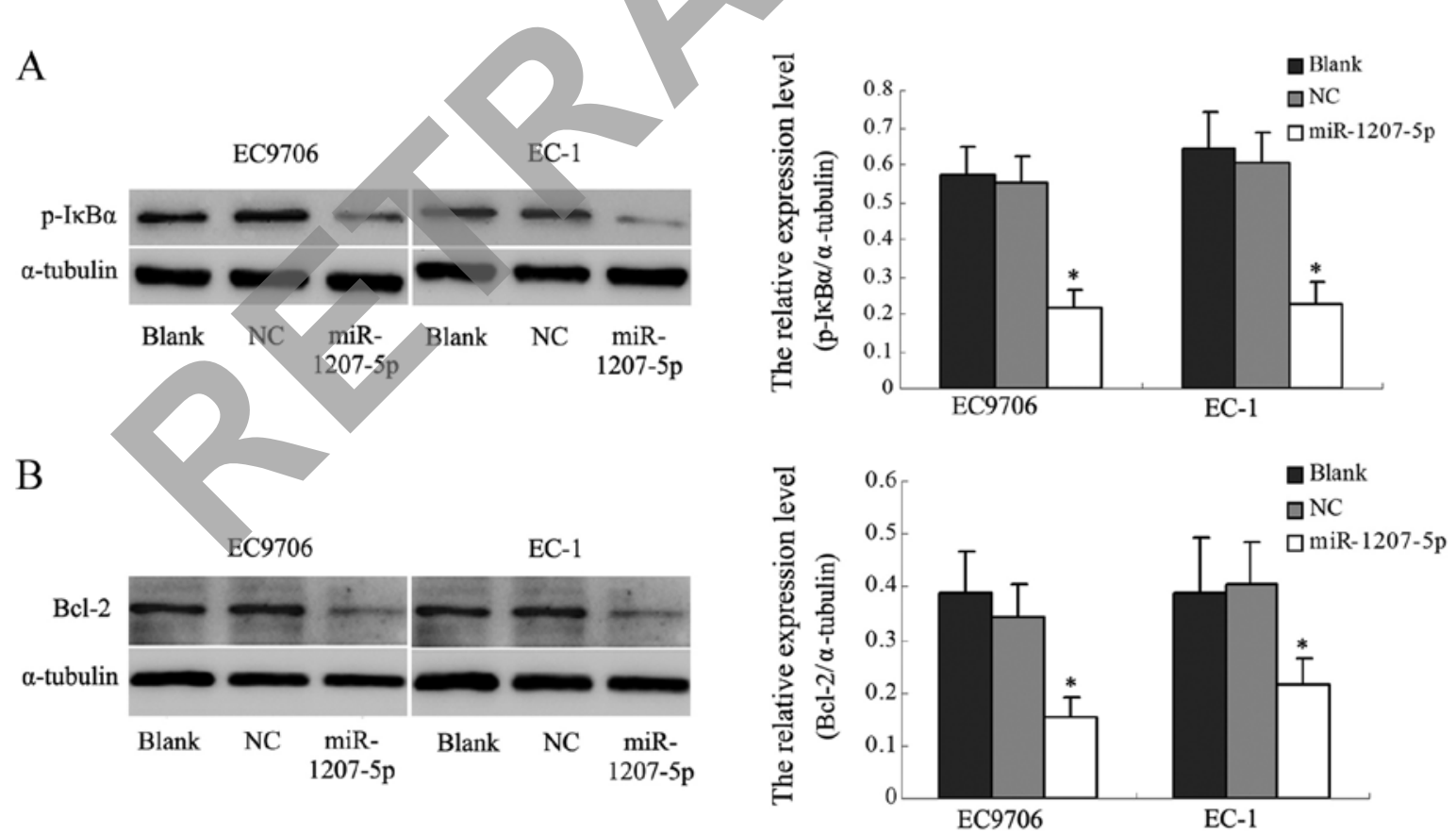

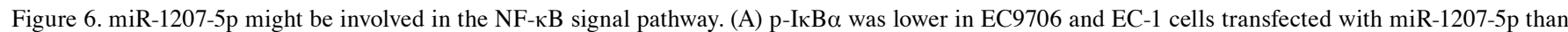
in the control cells. (B) Bcl-2 expression was downregulated in miR-1207-5p-transfected cells compared with the control cells. "P<0.05; miR-1207-5p, cells transfected with miR-1207-5p mimic; NC, cells transfected with scrambled miR-1207-5p negative control; blank, untransfected cells.

\section{Discussion}

Ectopic miRNAs have been reported in various cancers, and are involved in various cellular processes such as differentiation, invasion and apoptosis (26-28). Previous studies have indicated that miR-1207-5p was downregulated in several cancers $(11,13)$. Our study showed that the expressions of mature miR-1207-5p were significantly downregulated in central EC 
tissues compared with tissues from the tumor margin, and that it might be a useful biomarker in EC. In addition, the levels of miR-1207-5p in patients with EC were associated with lymph node metastases, the levels of tumor differentiation and pathological stages. To examine the effects of miR-1207-5p, we transfected the miR-1207-5p mimic into EC9706 and EC-1 cells. Upregulation of miR-1207-5p was observed to suppress cell proliferation and invasion and to promote cell apoptosis. These results implied that miR-1207-5p might be an inhibitor of EC, and contributes to the development, progression and metastasis of EC.

Our study showed that STOML-2 was negatively regulated by miR-1207-5p at the posttranscriptional level by binding to the 3'-UTR of STOML-2 mRNA in EC cells. Studies have revealed that this interaction could decrease the expression of STOML-2 in EC cells. Previous experiments showed that STOML-2 was overexpressed in various tumors, such as esophageal carcinoma, gastric adenocarcinoma, breast cancer and glioma. Levels of STOML-2 were much higher in central tumor tissues than in paired tissues, and STOML2-silenced cells showed decreased cell proliferation, invasive capability and adhesive ability in vitro (25). Accordingly, the level of STOML-2 was associated with tumor metastasis in breast cancer and pulmonary squamous cell carcinoma (29). Our study showed that the effect of STOML-2 on EC invasion needs to be further investigated. Our findings showed that miR-1207-5p might act as a suppressor of metastasis by targeting STOML-2.

Abnomal activation of $\mathrm{NF}-\kappa \mathrm{B}$ has been found in many types of cancer, including esophageal carcinoma (30-32); however, the activation mechanisms have not been elucidated. Accumulating publications have shown that miRNAs such as miR-146, miR-155, miR-21, and miR-301a have pathological relevance to $N F-\kappa B$ signaling $(33-35)$. The phosphorylation of $\mathrm{I} \kappa \mathrm{B} \alpha$ is a key step in NF- $\mathrm{NB}$ pathway activation, and $\mathrm{Bcl}-2$ is one of the classical NF- $\mathrm{NB}$ target genes. Bcl-2 is an antiapoptotic protein and promotes cell survival $(36,37)$. Previous research has shown that it was related to the early development of EC $(38,39)$. We found that upregulation of miR-1207-5p significantly inhibited STOML -2 expression and $\mathrm{I} \kappa \mathrm{B} \alpha$ phosphorylation. The expression of Bcl-2 was downregulated in miR-1207-5p-transfected cells. Studies have demonstrated that depletion of STOML-2 in glioma cells reduced NF- $\kappa$ B transcriptional activity (25); this finding was consistent with our results, and indicated that STOML-2 might be involved in the regulation of the $\mathrm{NF}-\kappa \mathrm{B}$ signaling pathway. The precise molecular mechanism underlying miR-1207-5p/STOML-2 and the $\mathrm{NF}-\kappa \mathrm{B}$ signaling pathway needs to be investigated further.

In conclusion, this study showed that miR-1207-5p was downregulated in EC, and that upregulation of miR-1207-5p suppressed cell proliferation, invasion and promotes apoptosis. Based on these results, we propose that miR-1207-5p might act as a potential therapeutic target in the treatment of esophageal carcinoma.

\section{Acknowledgements}

This study was supported by the National Natural Science Foundation of China (no. 81301726).

\section{References}

1. Lee RC and Ambros V: An extensive class of small RNAs in Caenorhabditis elegans. Science 294: 862-864, 2001.

2. Lau NC, Lim LP, Weinstein EG and Bartel DP: An abundant class of tiny RNAs with probable regulatory roles in Caenorhabditis elegans. Science 294: 858-862, 2001.

3. Ambros V: microRNAs: Tiny regulators with great potential. Cell 107: 823-826, 2001.

4. Hede K: Studies define role of microRNA in cancer. J Natl Cancer Inst 97: 1114-1115, 2005.

5. Cheng T, Hu C, Yang H, Cao L and An J: Transforming growth factor- $\beta$-induced miR-143 expression in regulation of non-small cell lung cancer cell viability and invasion capacity in vitro and in vivo. Int J Oncol 45: 1977-1988, 2014.

6. Chiyomaru T, Seki N, Inoguchi S, et al: Dual regulation of receptor tyrosine kinase genes EGFR and c-Met by the tumorsuppressive microRNA-23b/27b cluster in bladder cancer. Int J Oncol 46: 487-496, 2015.

7. Pei J, Robu V, Feder M, Cheung M, Neumann-Domer E, Talarchek J, Dulaimi E, Millenson MM and Testa JR: Copy neutral loss of heterozygosity in $20 \mathrm{q}$ in chronic lymphocytic leukemia/small lymphocytic lymphoma. Cancer Genet 207: 98-102, 2014.

8. Wang Y,Li M, Zang W, Ma Y, Wang N, Li P, Wang T and Zhao G: MiR-429 up-regulation induces apoptosis and suppresses invasion by targeting Bcl-2 and SP-1 in esophageal carcinoma. Cell Oncol Dordr 36:385-394, 2013.

9. Huang J, Zhang SY, Gao YM, Liu YF, Liu YB, Zhao ZG and Yang K: MicroRNAs as oncogenes or tumour suppressors in oesophageal cancer: Potential biomarkers and therapeutic targets. Cell Prolif 47: 277-286, 2014.

10. Chen Z, Li J, Tian L, et al: MiRNA expression profile reveals a prognostic signature for esophageal squamous cell carcinoma. Cancer Lett 350: 34-42, 2014.

11. Peña-Chilet M, Martínez MT, Pérez-Fidalgo JA, et al: MicroRNA profile in very young women with breast cancer. BMC Cancer 14: $529,2014$.

12. Mun J, Tam C, Chan G, Kim JH, Evans D and Fleiszig S: MicroRNA-762 is upregulated in human corneal epithelial cells in response to tear fluid and Pseudomonas aeruginosa antigens and negatively regulates the expression of host defense genes encoding RNase7 and ST2. PLoS One 8: e57850, 2013.

13. Chen L, Lü MH, Zhang D, et al: miR-1207-5p and miR-1266 suppress gastric cancer growth and invasion by targeting telomerase reverse transcriptase. Cell Death Dis 5: e1034, 2014.

14. Papagregoriou G, Erguler K, Dweep H, Voskarides K, Koupepidou P, Athanasiou Y, Pierides A, Gretz N, Felekkis KN and Deltas C: A miR-1207-5p binding site polymorphism abolishes regulation of HBEGF and is associated with disease severity in CFHR5 nephropathy. PLoS One 7: e31021, 2012.

15. Alvarez ML, Khosroheidari M, Eddy E and Kiefer J: Role of microRNA 1207-5P and its host gene, the long non-coding RNA Pvt1, as mediators of extracellular matrix accumulation in the kidney: Implications for diabetic nephropathy. PLoS One 8: e77468, 2013

16. Wang Y and Morrow JS: Identification and characterization of human SLP-2, a novel homologue of stomatin (band 7.2b) present in erythrocytes and other tissues. J Biol Chem 275: 8062-8071, 2000.

17. Owczarek CM, Treutlein HR, Portbury KJ, Gulluyan LM, Kola I and Hertzog PJ: A novel member of the STOMATIN/ EPB72/mec-2 family, stomatin-like 2 (STOML2), is ubiquitously expressed and localizes to HSA chromosome 9p13.1. Cytogenet Cell Genet 92: 196-203, 2001.

18. Lapatsina L, Brand J, Poole K, Daumke O and Lewin GR: Stomatin-domain proteins. Eur J Cell Biol 91: 240-245, 2012

19. Liu Z, Yang Y, Zhang Y, Ye X, Wang L and Xu G: Stomatin-like protein 2 is associated with the clinicopathological features of human papillary thyroid cancer and is regulated by TGF- $\beta$ in thyroid cancer cells. Oncol Rep 31: 153-160, 2014.

20. Cao W, Zhang B, Liu Y, et al: High-level SLP-2 expression and HER-2/neu protein expression are associated with decreased breast cancer patient survival. Am J Clin Pathol 128: 430-436, 2007.

21. Cui Z, Zhang L, Hua Z, Cao W, Feng W and Liu Z: Stomatinlike protein 2 is overexpressed and related to cell growth in human endometrial adenocarcinoma. Oncol Rep 17: 829-833, 2007. 
22. Zhang L, Ding F, Cao W, Liu Z, Liu W, Yu Z, Wu Y, Li W, Li Y and Liu Z: Stomatin-like protein 2 is overexpressed in cancer and involved in regulating cell growth and cell adhesion in human esophageal squamous cell carcinoma. Clin Cancer Res 12: 1639-1646, 2006.

23. Cao W, Zhang B, Li J, Liu Y, Liu Z and Sun B: SLP-2 overexpression could serve as a prognostic factor in node positive and HER2 negative breast cancer. Pathology 43: 713-718, 2011.

24. Cao W, Zhang B, Ding F, Zhang W, Sun B and Liu Z: Expression of SLP-2 was associated with invasion of esophageal squamous cell carcinoma. PLoS One 8: e63890, 2013.

25. Song L, Liu L, Wu Z, Lin C, Dai T, Yu C, Wang X, Wu J, Li M and Li J: Knockdown of stomatin-like protein 2 (STOML2) reduces the invasive ability of glioma cells through inhibition of the NF- $\mathrm{B}$ B/MMP-9 pathway. J Pathol 226: 534-543, 2012.

26. Lu J, Getz G, Miska EA, et al: MicroRNA expression profiles classify human cancers. Nature 435: 834-838, 2005.

27. Adams BD, Kasinski AL and Slack FJ: Aberrant regulation and function of microRNAs in cancer. Curr Biol 24: R762-R776, 2014.

28. Bouyssou JM, Manier S, Huynh D, Issa S, Roccaro AM and Ghobrial IM: Regulation of microRNAs in cancer metastasis. Biochim Biophys Acta 1845: 255-265, 2014.

29. Chang D, Ma K, Gong M, Cui Y, Liu ZH, Zhou XG, Zhou CN and Wang TY: SLP-2 overexpression is associated with tumour distant metastasis and poor prognosis in pulmonary squamous cell carcinoma. Biomarkers 15: 104-110, 2010.

30. Gasparini C, Celeghini C, Monasta L and Zauli G: NF-kappaB pathways in hematological malignancies. Cell Mol Life Sci 71: 2083-2102, 2014.

31. Tong L, Yuan Y and Wu S: Therapeutic microRNAs targeting the NF-kappa B signaling circuits of cancers. Adv Drug Deliv Rev 81: 1-15, 2015.
32. Abdel-Latif MM, O'Riordan J, Windle HJ, Carton E, Ravi N, Kelleher D and Reynolds JV: NF-kappaB activation in esophageal adenocarcinoma: Relationship to Barrett's metaplasia, survival, and response to neoadjuvant chemoradiotherapy. Ann Surg 239: 491-500, 2004.

33. Gong H, Song L, Lin C, Liu A, Lin X, Wu J, Li M and Li J: Downregulation of miR-138 sustains NF- $\kappa$ B activation and promotes lipid raft formation in esophageal squamous cell carcinoma. Clin Cancer Res 19: 1083-1093, 2013.

34. Bhaumik D, Scott GK, Schokrpur S, Patil CK, Campisi J and Benz CC: Expression of microRNA-146 suppresses NF-kappaB activity with reduction of metastatic potential in breast cancer cells. Oncogene 27: 5643-5647, 2008.

35. Kumar V, Palermo R, Talora C, et al: Notch and NF- $\kappa B$ signaling pathways regulate miR-223/FBXW7 axis in T-cell acute lymphoblastic leukemia. Leukemia 28: 2324-2335, 2014.

36. Hardwick JM, Chen YB and Jonas EA: Multipolar functions of BCL-2 proteins link energetics to apoptosis. Trends Cell Biol 22: 318-328, 2012.

37. Wood WG, Igbavboa U,Muller WE and Eckert GP: Statins, Bcl-2, and apoptosis: Cell death or cell protection? Mol Neurobiol 48: 308-314, 2013.

38. Sarbia M, Bittinger F, Porschen R, Verreet P, Dutkowski P, Willers $\mathrm{R}$ and Gabbert HE: bcl-2 expression and prognosis in squamous-cell carcinomas of the esophagus. Int J Cancer 69: 324-328, 1996.

39. Torzewski M, Sarbia M, Heep H, Dutkowski P, Willers R and Gabbert HE: Expression of Bcl-X(L), an antiapoptotic member of the Bcl-2 family, in esophageal squamous cell carcinoma. Clin Cancer Res 4: 577-583, 1998 . 